\title{
Reversibly Photoswitchable Dual-Color Fluorescence and Controlled Release Properties of Polymeric Nanoparticles
}

Desheng Wang, ${ }^{\text {a }}$ Tingting Zhang, ${ }^{\mathrm{b}}$ Bo Wu, ${ }^{\mathrm{a}}$ Chunxiao Ye, ${ }^{\mathrm{a}}$ Zhengyang Wei, Ziquan Cao, ${ }^{\text {G Guojie Wang*,a }}$

a School of Materials Science and Engineering, University of Science and Technology Beijing, Beijing 100083, China;

b Yantai Engineering and Technology College, Yantai 264000, China.

AUTHOR EMAIL ADRESS: guojie.wang@mater.ustb.edu.cn 
Synthesis of Spiropyran Derivative (SP-Br). SP-OH $\left(1.056 \mathrm{~g}, 3 \times 10^{-3} \mathrm{~mol}\right)$ and $\mathrm{Et}_{3} \mathrm{~N}$ $(2 \mathrm{~mL})$ were dissolved in DCM $(40 \mathrm{~mL})$ at $0{ }^{\circ} \mathrm{C}$. Subsequently, bromoacetyl bromide $\left(1 \mathrm{~mL}, 1.3 \times 10^{-3} \mathrm{~mol}\right)$ was dissolved in DCM $(5 \mathrm{~mL})$ and added dropwise to the above solution, followed by stirring at room temperature for $24 \mathrm{~h}$. Then the mixed solution was neutralized with saturated sodium bicarbonate solution and wished with deionized water. The collected organic layer was dried over anhydrous $\mathrm{MgSO}_{4}$, and the $\mathrm{DCM}$ was removed at $40{ }^{\circ} \mathrm{C}$ by rotary evaporation under reduced pressure to obtain the red product $\mathrm{SP}-\mathrm{Br}$.

Synthesis of Poly(ethylene glycol) methyl ether acrylate (MPEG-A). Briefly, MPEG (1.9 $\left.\mathrm{g}, 1 \times 10^{-3} \mathrm{~mol}\right)$, dissolved in anhydrous DCM $(10 \mathrm{~mL})$, was mixed with triethylamine $\left(0.55 \mathrm{~mL}, 4 \times 10^{-3} \mathrm{~mol}\right)$ and cooled to $0{ }^{\circ} \mathrm{C}$. Following the dropwise addition of acryloyl chloride $\left(0.24 \mathrm{~mL}, 3 \times 10^{-3} \mathrm{~mol}\right)$, the mixture was stirred at $0{ }^{\circ} \mathrm{C}$ for $2 \mathrm{~h}$, then stirred for $24 \mathrm{~h}$ at room temperature. Then the mixture was washed with dilute $\mathrm{HCl}$ and precipitated with hexane to obtain poly(ethylene glycol) methyl ether acrylate (MPEG-A).

Synthesis of Naphthalimide Derivative (NAPH-Br). The synthesis of NAPH-Br included: (i) 4-bromo-1,8-naphthalimide was prepared starting from 4-bromo-1,8naphthalic anhydride $\left(5.54 \mathrm{~g}, 2 \times 10^{-2} \mathrm{~mol}\right)$ with aqueous ammonia $(30 \mathrm{~mL})$ at $45^{\circ} \mathrm{C}$ for $8 \mathrm{~h}$. The residue was washed with water and dried to obtain the crude product as brown powder. (ii) 4-hexylamino-1,8-naphthalimide was prepared starting from 4-bromo-1,8naphthalimide $\left(2.76 \mathrm{~g}, 1 \times 10^{-2} \mathrm{~mol}\right)$ with hexylamine $\left(3.03 \mathrm{~g}, 3 \times 10^{-2} \mathrm{~mol}\right)$ in DMSO $(50$ $\mathrm{mL}$ ) at $100{ }^{\circ} \mathrm{C}$ for $4 \mathrm{~h}$. Then the reaction system was first cooled to room temperature, and the mixture was poured into deionized water $(500 \mathrm{~mL})$. The precipitate was filtered and washed with deionized water, and dried to give orange product 4-hexylamino-1,8naphthalimide. (iii) 4-hexylamino-1,8-naphthalimide (1.48 g, $\left.5 \times 10^{-3} \mathrm{~mol}\right)$ and $\mathrm{K}_{2} \mathrm{CO}_{3}$ $\left(1.03 \mathrm{~g}, 7.5 \times 10^{-3} \mathrm{~mol}\right)$ were added to DMF $(10 \mathrm{ml})$, and the mixed mixture was stirred at $60{ }^{\circ} \mathrm{C}$ for $20 \mathrm{~min}$, then adding 1,4-dibromobutane $(4 \mathrm{~mL})$ at $40{ }^{\circ} \mathrm{C}$ for $24 \mathrm{~h}$ (monitored by TLC, eluent, chloroform/methanol, 40/1, v/v). The reaction solution was added to $\operatorname{DCM}(100 \mathrm{~mL})$ and washed with deionized water $(500 \mathrm{~mL})$. Then the collected organic 
layer was concentrated with rotary-evaporator to gain the crude product. The crude product was further purified by column chromatography (ethyl acetate/petroleum ether, $1 / 5, \mathrm{v} / \mathrm{v})$ to yield yellow product NAPH-Br.

Preparation of Polymeric Nanoparticles and Controlled Release of Coumarin 102. In a typical experiment, the copolymer $(2 \mathrm{mg})$ was dissolved in DMF $(1 \mathrm{~mL})$. Then under vigorous stirring, deionized water $(1 \mathrm{~mL})$ was added to the solution to induce the formation of nanoparticles. After stirring for $3 \mathrm{~h}$, the formation was stabilized by quickly adding another $9 \mathrm{~mL}$ of deionized water. Finally, the solution was added to dialysis sack $(\mathrm{Mw}, 500)$ and dialyzed against deionized water for $24 \mathrm{~h}$ to remove DMF. As to the nanoparticles encapsulated with Coumarin 102, the copolymer (2 mg) and Coumarin $102(0.5 \mathrm{mg})$ was fully dissolved in DMF (1 mL). Similarly, deionized water was added and DMF was removed to obtain the nanoparticles solution loaded with Coumarin 102. When Coumarin 102 is encapsulated into nanoparticles, it can exhibit a strong emission, while the emission intensity of Coumarin 102 decreases drastically when it is released from the nanoparticles since Coumarin 102 is almost insoluble in water. The controlled release behaviors of Coumarin 102 under the stimuli of $\mathrm{pH}$ and UV irradiation were investigated according to the change of fluorescence intensity. For the controlled release under UV irradiation, the nanoparticles solution loaded with Coumarin 102 was placed under a LED lamp $\left(365 \mathrm{~nm}, 30 \mathrm{~mW} / \mathrm{cm}^{2}\right)$ at $\mathrm{pH} 7$. For the controlled release at $\mathrm{pH} 5.5$, the sample was adjusted to $\mathrm{pH} 5.5$ by adding aqueous $\mathrm{HCl}$ solutions. For the controlled release under combined stimulation, the sample was adjusted to $\mathrm{pH} 5.5$ and irradiated with UV light. After each stimulation for an appropriate time interval, the corresponding fluorescence spectra were recorded. 


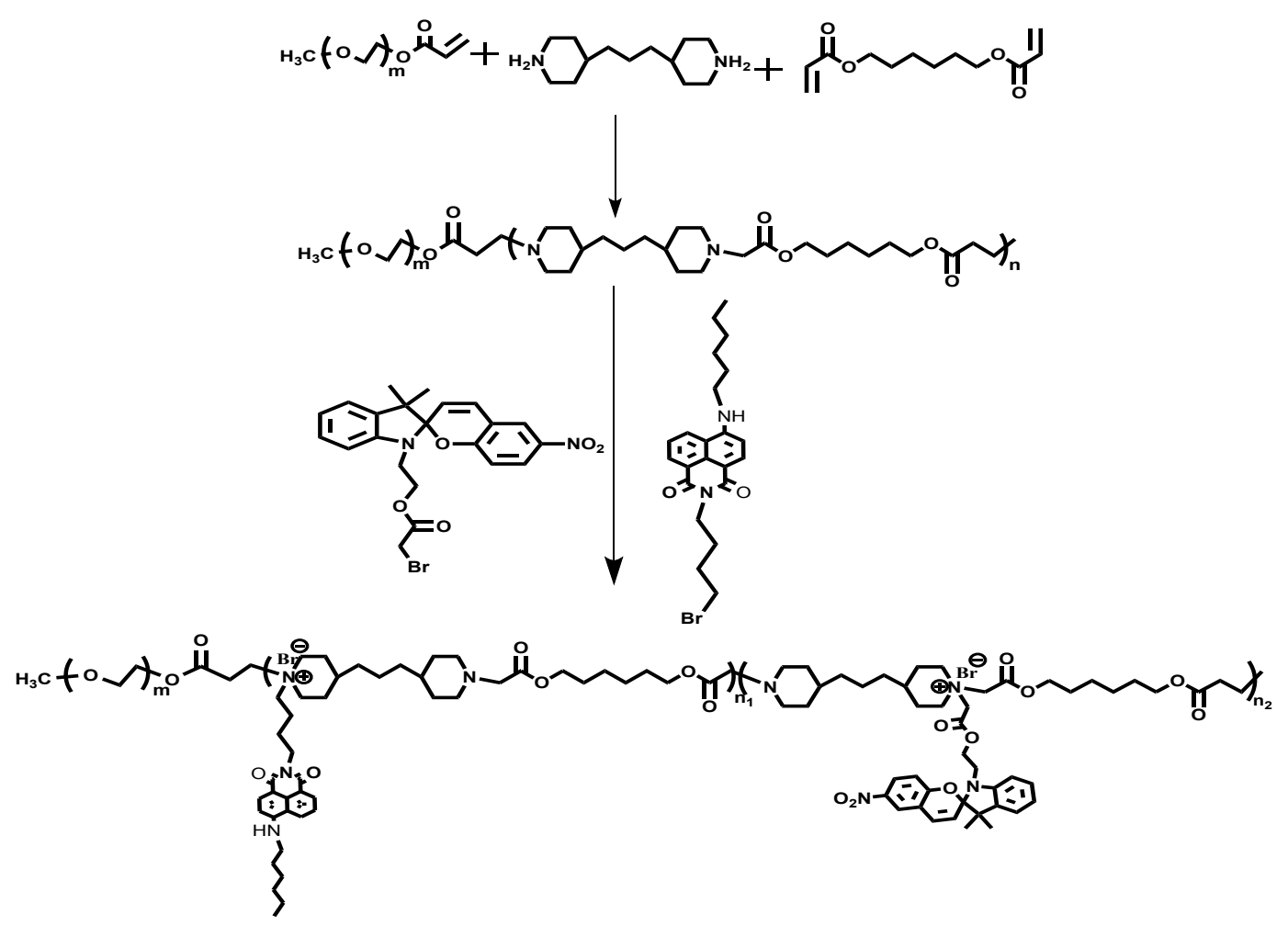

Figure S1. Synthetic route of the copolymers P1 and P2.

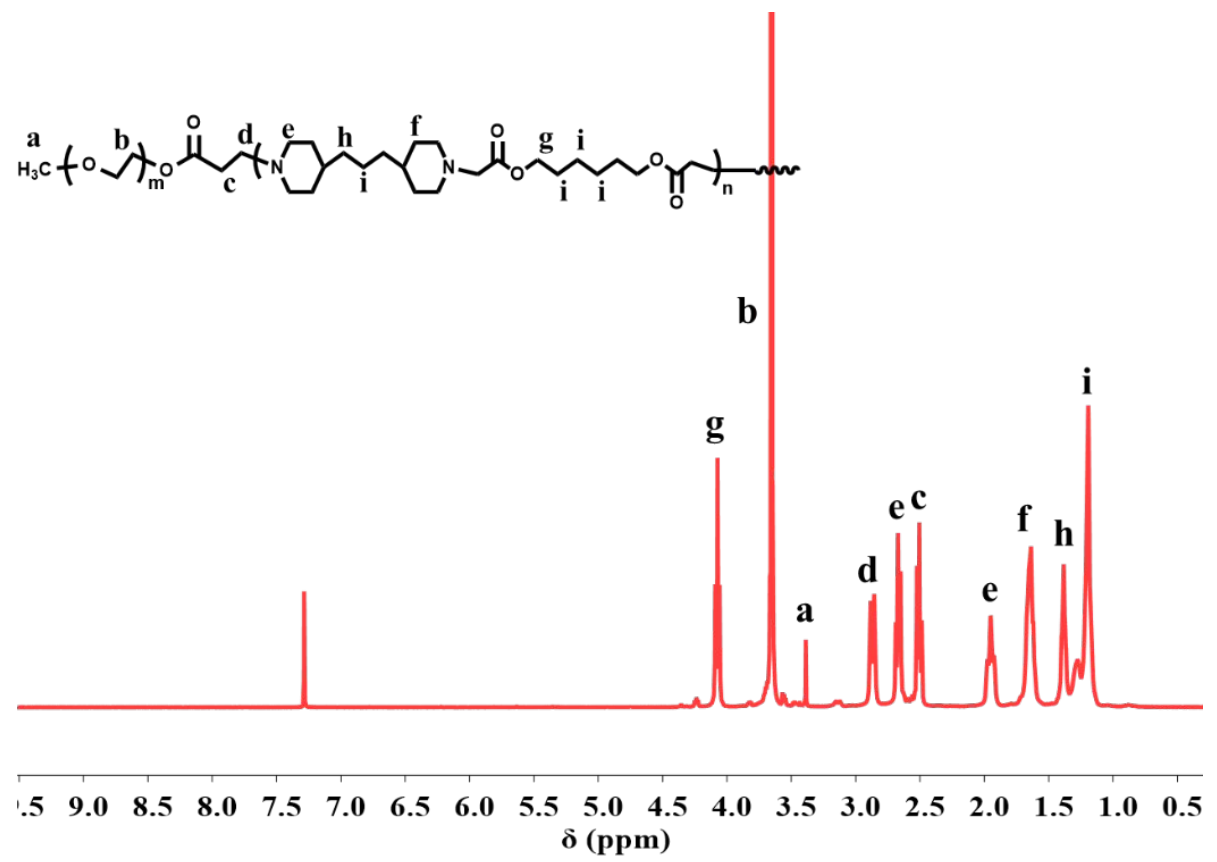

Figure S2. ${ }^{1} \mathrm{H}$ NMR spectrum of MPEG-PAE. 


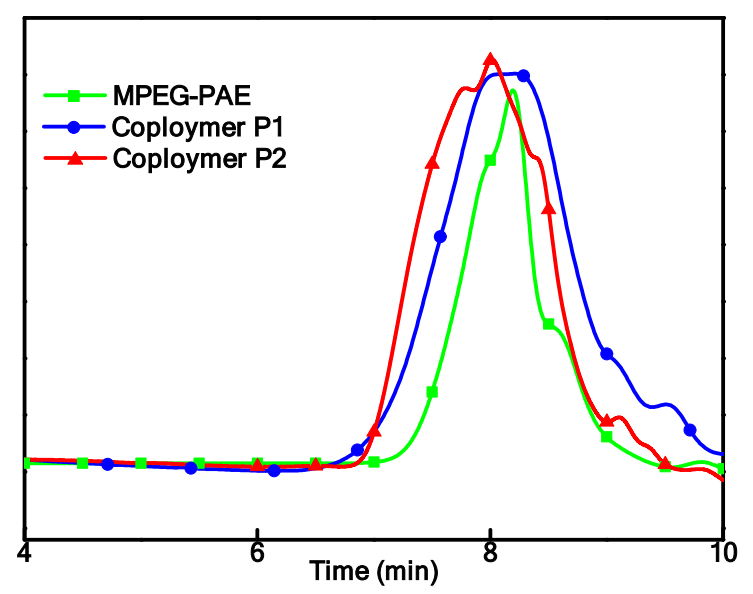

Figure S3. GPC traces of MPEG-PAE and the Copolymers P1 and P2.

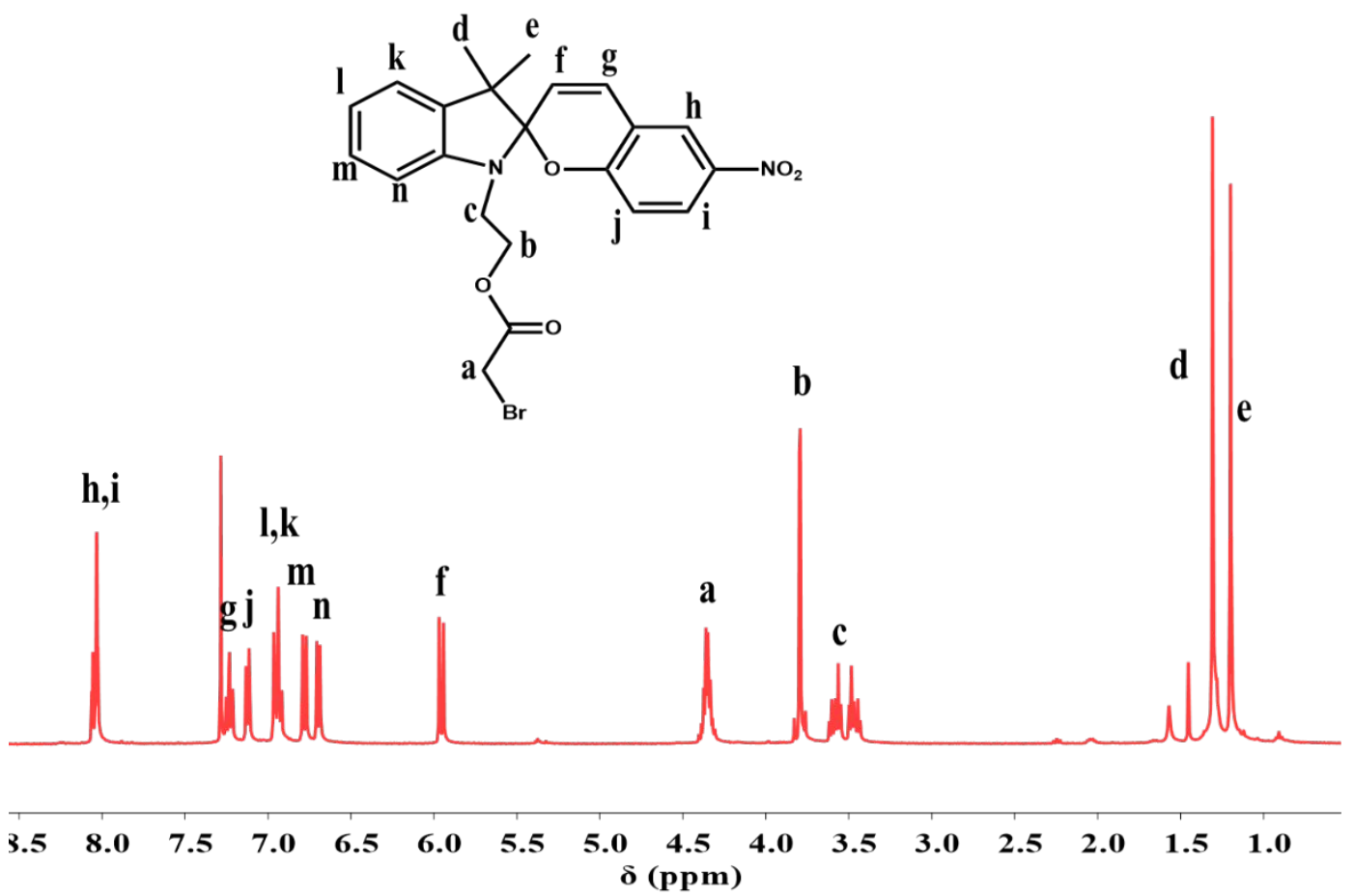

Figure S4. ${ }^{1} \mathrm{H}$ NMR spectrum of SP-Br. 


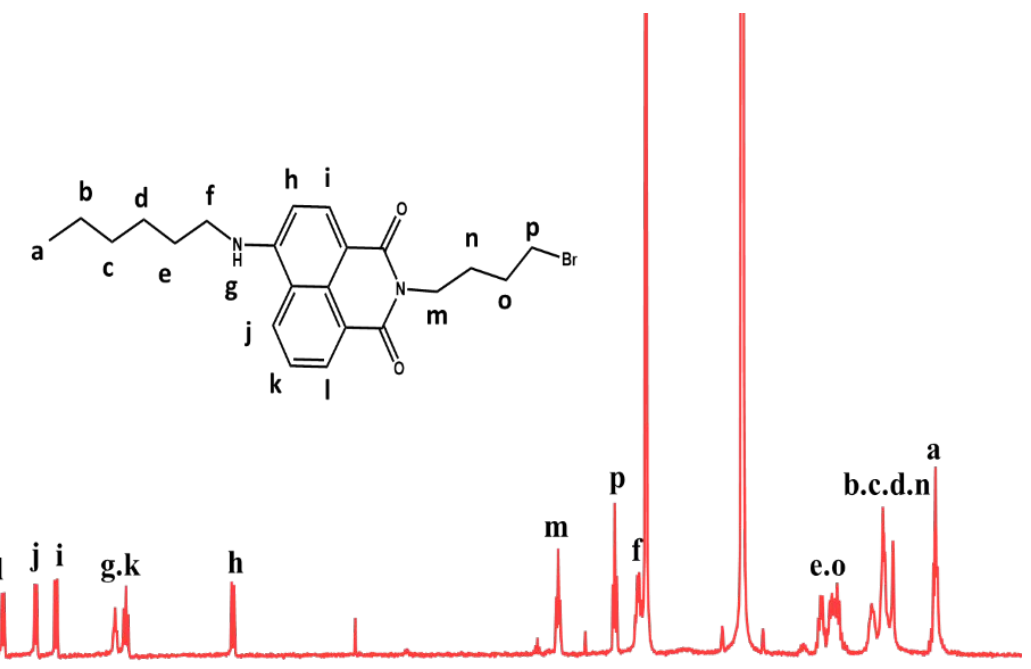

$\begin{array}{lllllllllllllllllllll}9.0 & 8.5 & 8.0 & 7.5 & 7.0 & 6.5 & 6.0 & 5.5 & \begin{array}{c}5.0 \\ 4.0\end{array} & 4.5 & 4.0 & 3.5 & 3.0 & 2.5 & 2.0 & 1.5 & 1.0 & 0.5\end{array}$

Figure S5. ${ }^{1} \mathrm{H}$ NMR spectrum of NAPH-Br in DMSO.

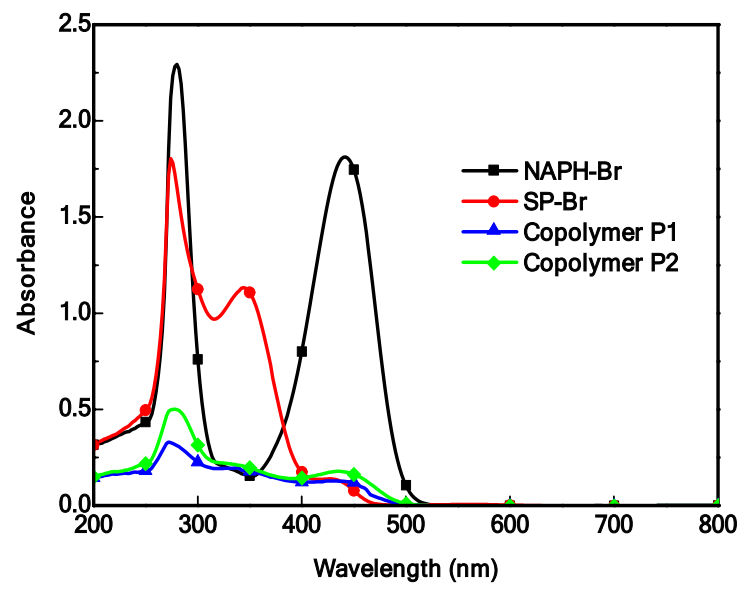

Figure S6. UV-Vis absorbance spectra of Copolymers P1and P2, SP-Br and NAPH-Br with concentration of $0.05 \mathrm{mg} / \mathrm{ml}$ in DMF.

Figure S6 shows the absorbance spectra of Copolymers P1 and P2, SP-Br and NAPHBr with same concentration. The molar absorptivity $\varepsilon\left(\lambda_{\max }\right)$ of the spiropyran and naphthalimide chromophores in the copolymers can be considered to be the same as that of the corresponding molecules $\mathrm{SP}-\mathrm{Br}$ and NAPH-Br. The degrees of functionalization (DF) of SP and NAPH in the copolymer P1 were calculated to be 9.5 $\%$ and $4.8 \%$ respectively, by contrasting the intensity of absorption band at $340 \mathrm{~nm}$ belonging to SP and $440 \mathrm{~nm}$ belonging to NAPH. Correspondingly, the DF of SP and NAPH in the copolymer P2 were calculated to be $9.7 \%$ and $9.3 \%$, respectively. 

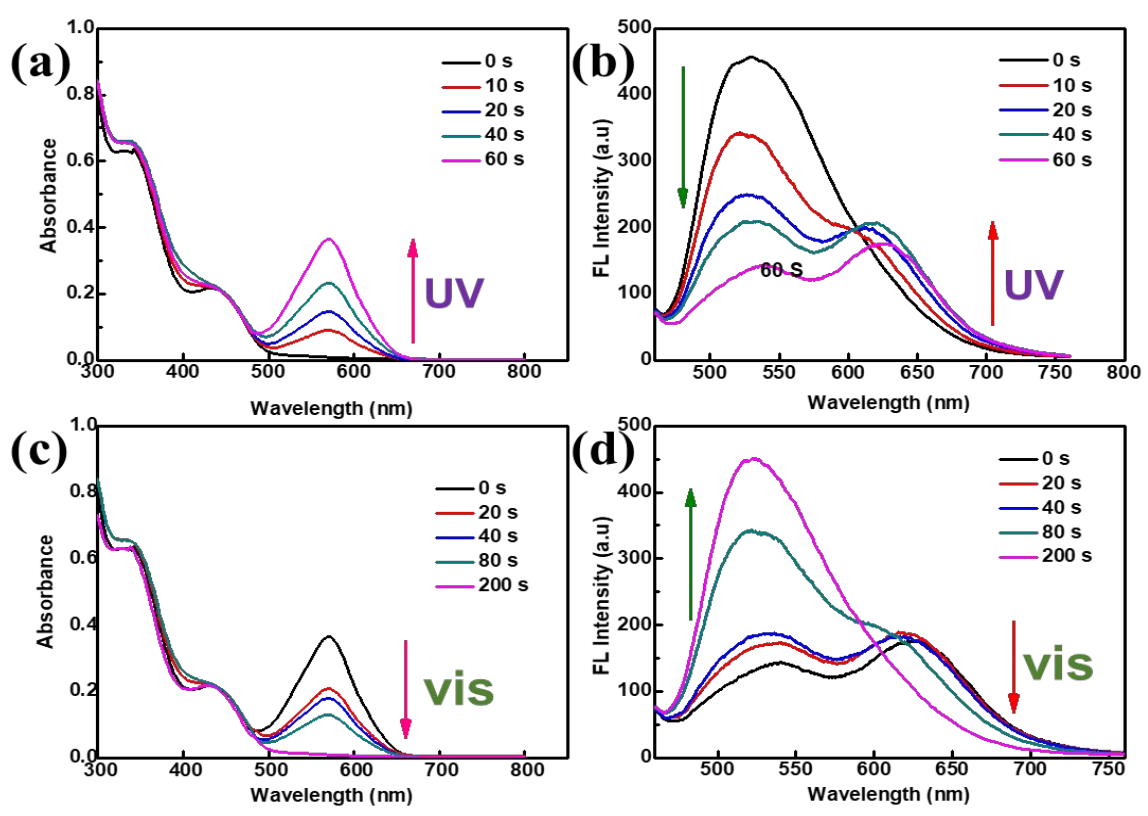

Figure S7. (a) UV-Vis spectra of the nanoparticles of P1 under the irradiation of UV light $\left(365 \mathrm{~nm}, 30 \mathrm{~mW} / \mathrm{cm}^{2}\right)$ for different time; (b) Fluorescence spectra of the nanoparticles of P1 under the irradiation of UV light $\left(365 \mathrm{~nm}, 30 \mathrm{~mW} / \mathrm{cm}^{2}\right)$ for different time (excited at $440 \mathrm{~nm}$ ); (c) UV-Vis spectra of the nanoparticles of P1 after UV irradiation and then under the irradiation of green light $\left(520 \mathrm{~nm}, 30 \mathrm{~mW} / \mathrm{cm}^{2}\right)$; (d) Fluorescence spectra of the nanoparticles of P1 after UV irradiation and then under the irradiation of green light $\left(520 \mathrm{~nm}, 30 \mathrm{~mW} / \mathrm{cm}^{2}\right)$ for different time (excited at $440 \mathrm{~nm}$ ).

Table S1. The photophysical properties of nanoparticles of P2.

\begin{tabular}{|l|l|l|l|}
\hline Fluorophore & $\lambda_{\mathrm{ab}}(\mathrm{nm})^{\mathrm{a}}$ & $\lambda_{\mathrm{em}}, \mathrm{nm}\left(\Phi_{\mathrm{F}}, \%\right)^{\mathrm{b}}$ & $\lambda_{\mathrm{em}}, \mathrm{nm}\left(\Phi_{\mathrm{F}}, \%\right)^{\mathrm{c}}$ \\
\hline NAPH-Br (donor) & 440 & $550(10.4)$ & $550(4.12)$ \\
\hline SP-Br (acceptor) & 365 & -- & $630(3.71)$ \\
\hline
\end{tabular}

a Determined in DMF.

${ }^{\mathrm{b}}$ Emission maximum in nanoparticles before UV irradiation.

${ }^{\mathrm{c}}$ Emission maximum in nanoparticles after $40 \mathrm{~s} \mathrm{UV}$ irradiation $\left(365 \mathrm{~nm}, 30 \mathrm{~mW} / \mathrm{cm}^{2}\right)$. Note: the quantum yields $\left(\Phi_{\mathrm{F}}\right)$ are determined by using fluorescein in sodium hydroxide solution $\left(0.1 \mathrm{M}, \Phi_{\mathrm{R}}=0.95\right)$ and rhodamine B in deionized water $\left(\Phi_{\mathrm{R}}=0.31\right)$ as reference, respectively. 

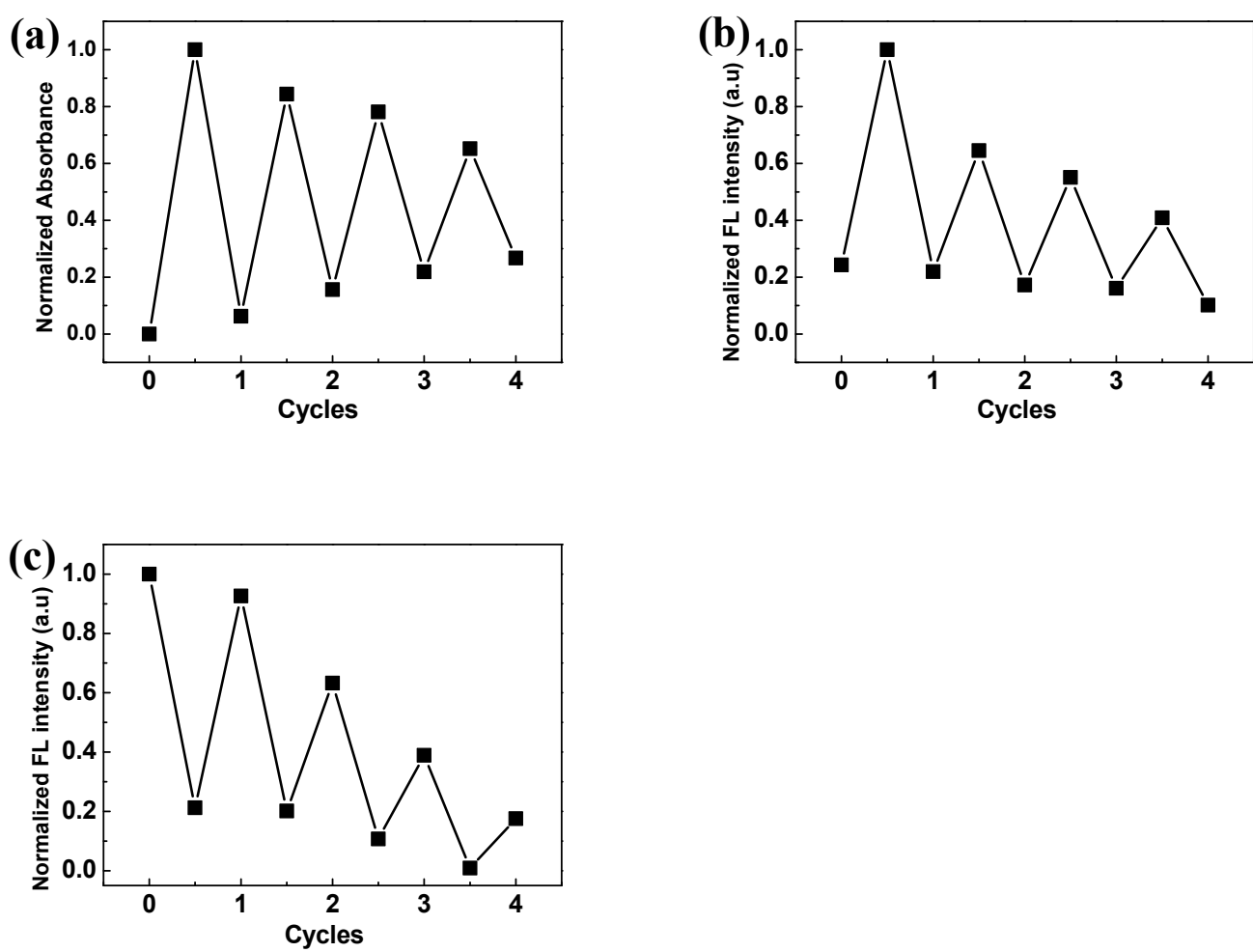

Figure S8. (a) UV-Vis absorbance changes of the nanoparticles of P2 at $530 \mathrm{~nm}$ upon alternate UV (40 s) and visible light (200 s) irradiation cycles. (b) Fluorescence changes of the nanoparticles of P2 at $630 \mathrm{~nm}$ upon alternate UV (40 s) and visible light (200 s) irradiation cycles. (c) Fluorescence changes of the nanoparticles of P2 at $550 \mathrm{~nm}$ upon alternate UV (40 s) and visible light (200 s) irradiation cycles. 


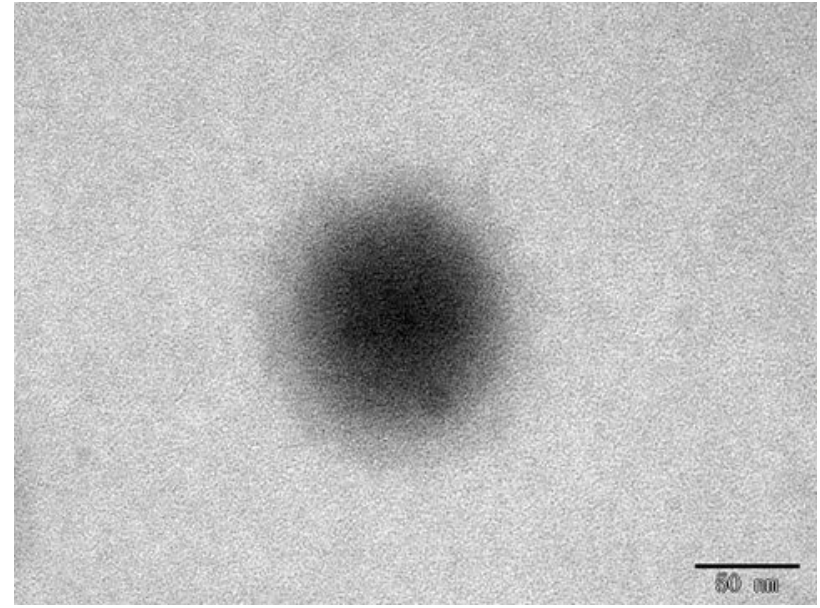

Figure S9. High-resolution TEM image of the initial nanoparticle.

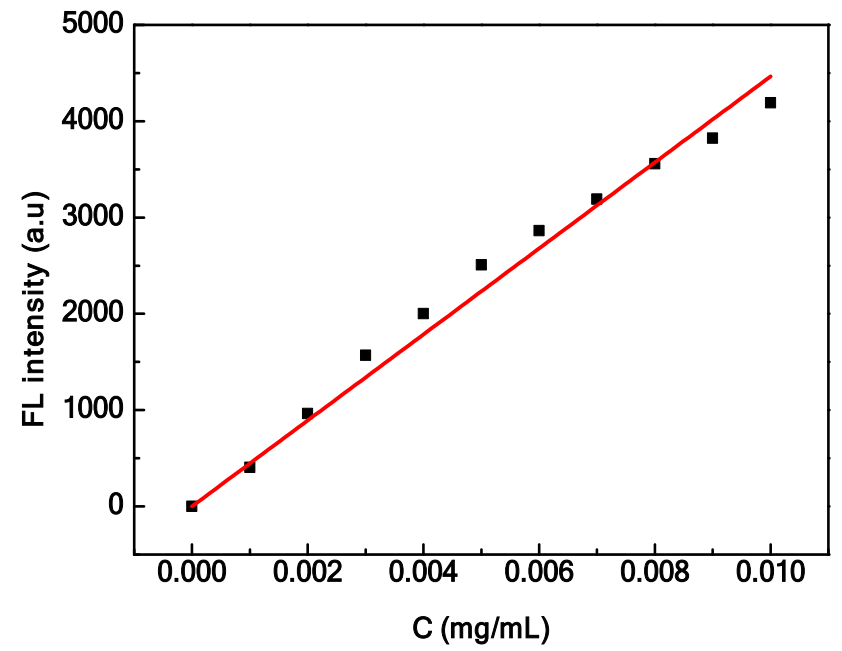

Figure S10. Plots of fluorescence emission intensity of Coumarin 102 at $490 \mathrm{~nm}$ at low concentrations in DMF.

Figure S10 shows that the fluorescence emission intensity increases with the increase of the concentration of Coumarin 102 linearly at low concentrations. The loading efficiency of Coumarin 102 in nanoparticles of $\mathrm{P} 2$ is $1.0 \%$, evaluated by the fluorescence intensity at $490 \mathrm{~nm}$. The release profiles of Coumarin 102 from the polymeric nanoparticles was calculated from the fluorescence decrease divided by the primary fluorescence intensity. 


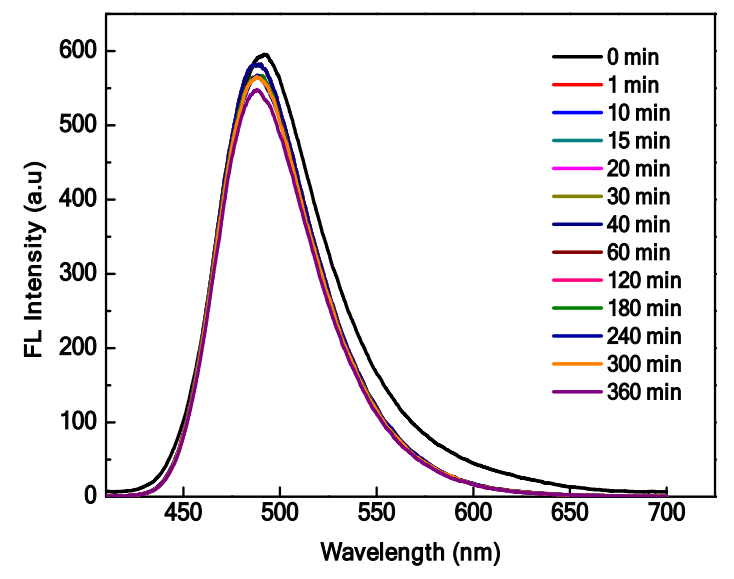

Figure S11. Fluorescence spectra of nanoparticles loaded with Coumarin 102 in water without stimulation for different time.

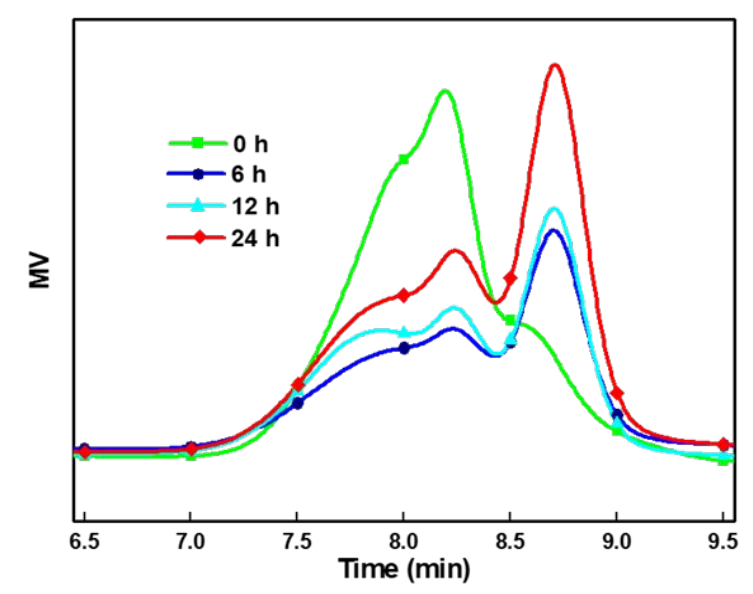

Figure S12. Normalized GPC traces of the synthesized MPEG-PAE hydrolyzed for different time in $\mathrm{pH} 5.5$ at $25^{\circ} \mathrm{C}$.

Figure S10 shows the normalized GPC traces of the synthesized MPEG-PAE hydrolyzed for different time in $\mathrm{pH} 5.5$ at $25^{\circ} \mathrm{C}$, from which it can be seen that the ratio of integral areas of the peak centered at 8.7 minutes to integral areas of the peak centered at 8.3 minutes gradually increased with the increase of time, which were attributed to the degradation of PAE by hydrolysis of ester bonds. 


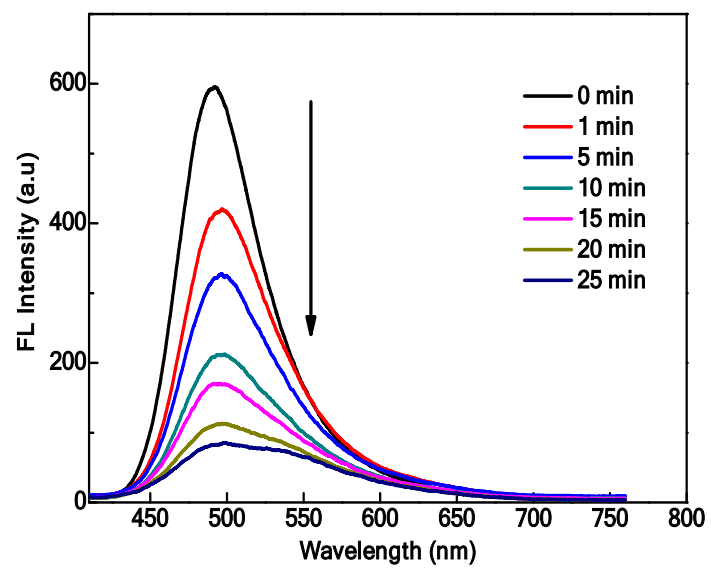

Figure S13. Fluorescence spectra of nanoparticles loaded with Coumarin 102 under UV light irradiation at $\mathrm{pH} 5.5$ for different time.

(a)

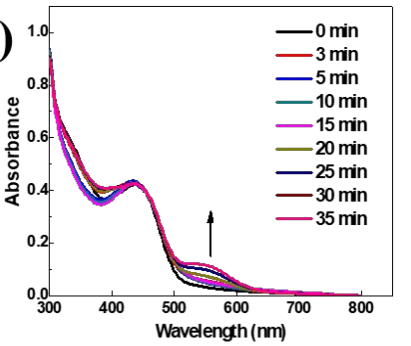

(b)

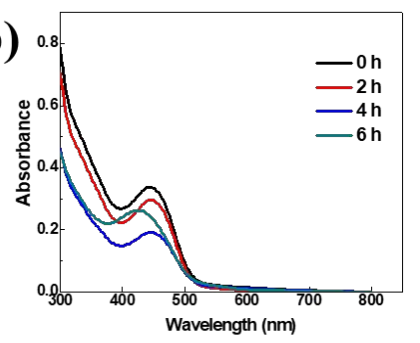

(c)

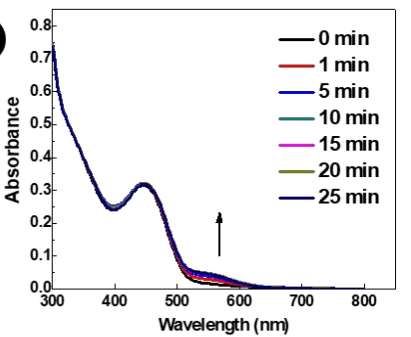

Figure S14. Absorbance spectra of nanoparticles loaded with Coumarin 102 under the stimuli: (a) UV light irradiation $\left(30 \mathrm{~mW} / \mathrm{cm}^{2}\right)$ at $\mathrm{pH} 7$; (b) at $\mathrm{pH} 5.5$; (c) UV light irradiation $\left(30 \mathrm{~mW} / \mathrm{cm}^{2}\right)$ at $\mathrm{pH} 5.5$. 